\title{
Substituição da Valva Aórtica por Via Percutânea: Uma Nova Técnica Revoluciona o Tratamento da Estenose Aórtica
}

Ver artigo relacionado na página 398

\author{
Eberhard Grube', Lutz Buellesfeld'
}

$\Delta$ substituição cirúrgica da valva aórtica era, e ainda é, padrão de referência para pacientes com estenose grave sintomática. No entanto, apesar do mau prognóstico com o tratamento medicamentoso, muitos pacientes não se submetem a cirurgia em decorrência do alto risco operatório, causado por co-morbidades como hipertensão pulmonar, doença pulmonar obstrutiva grave, cirurgia cardíaca prévia, aorta em porcelana, etc.

A substituição da valva aórtica por via percutânea utilizando próteses montadas em stents surgiu como uma nova e promissora opção nos últimos anos, oferecendo alternativa segura de tratamento a candidatos para os quais a substituição cirúrgica da valva aórtica não é considerada segura.

No momento, duas técnicas diferentes estão disponíveis comercialmente: a prótese balão-expansível Cribier-Edwards ou prótese Edwards-SAPIEN (Edwards Lifesciences, Irvine, Califórnia, Estados Unidos) e a prótese CoreValve ReValving (Corevalve Inc., Irvine, Califórnia, Estados Unidos). Desde o início de sua utilização clínica, cerca de três a cinco anos atrás, cada vez mais pacientes vêm sendo tratados com esses dispositivos, principalmente na Europa, com aumento exponencial nos últimos dezoito meses.

Nesta edição da Revista Brasileira de Cardiologia Invasiva, Sarmento-Leite et al. ${ }^{1}$ relatam os resultados do implante percutâneo de válvula aórtica realizado nos três primeiros pacientes na Região Sul do Brasil. O artigo demonstra com precisão que a substituição percutânea da valva aórtica utilizando a prótese CoreValve $18 \mathrm{~F}$ é técnica factível e confiável. Estudos anteriores demonstraram que a taxa do sucesso agudo do dispositivo é superior a 97\% com a atual prótese CoreValve ReValving. Quando a prótese é implantada com sucesso, a condição hemodinâmica melhora imediatamente. Qualquer gradiente de pressão préintervenção pode ser reduzido a um gradiente médio típico de $8 \mathrm{mmHg}$ a $10 \mathrm{mmHg}$ com o dispositivo já implantado. A regurgitação aórtica leve é comum após o procedimento e provavelmente está relacionada à cobertura incompleta das comissuras da valva nativa, principalmente nos casos com calcificações focais compactas.

A curva de aprendizagem do procedimento nos últimos três anos incluiu o desenvolvimento de várias técnicas de implante, assim como de várias estratégias intervencionistas de resgate para lidar com resultados iniciais aquém do ideal. Todas essas técnicas, assim como a habilidade para identificar as indicações corretas para seu uso, sem dúvida exigem operadores experientes e logística adequada. Por esse motivo, existe um rigoroso programa de treinamento, tanto para os centros já habilitados como para os novos, para manter esses padrões.

Com isso, a incidência de complicações graves é cada vez menor. Acidentes vasculares cerebrais ocorrem em menos de 3\% dos casos e a mortalidade periprocedimento está próxima de zero, nas últimas séries de implante percutâneo de válvula aórtica. A mortalidade aos trinta dias, principal parâmetro de segurança, passou de 40\% no início para 9,8\% atualmente, para a geração atual da prótese CoreValve. A maioria dessas mortes está mais relacionada às co-morbidades do paciente que aos efeitos colaterais do procedimento. Podemos prever que a mortalidade aos trinta dias irá cair substancialmente, assim que uma população de menor risco for aceita para esse procedimento. Pacientes de 50 anos portadores de estenose da valva aórtica isolada ainda devem ser encaminhados para substituição cirúrgica da valva, conforme indicam as

1 HELIOS Heart Center Siegburg - Siegburg, Alemanha.

Correspondência: Eberhard Grube. Department of Cardiology/Angiology - HELIOS Heart Center Siegburg - Ringstrasse 49 - Siegburg, Germany - 53721 E-mail: grubee@aol.com

Recebido em: 9/12/2008 • Aceito em: 12/12/2008 

Aórtica. Rev Bras Cardiol Invas. 2008;16(4):387-388.

diretrizes atuais, pela inexistência de dados do acompanhamento a longo prazo. No entanto, por causa do rápido progresso que o implante percutâneo de válvula aórtica vem apresentando, essa recomendação certamente será questionada dentro de alguns anos.

A triagem bem feita é, sem dúvida, o principal fator para a elevada taxa de sucesso do dispositivo. Vários estudos estão em andamento, buscando reconhecer e validar cientificamente instrumentos de triagem para identificação de pacientes morfologicamente adequados. Atualmente, entre os fatores que tornam o paciente mau candidato para o implante percutâneo da prótese CoreValve estão artérias femoral e ilíaca com diâmetro inferior a $6 \mathrm{~mm}$, trajeto arterial periférico muito tortuoso e calcificado, e anéis valvares muito pequenos ou muito grandes.

Em síntese, o implante da prótese CoreValve Revalving representa atualmente uma opção de tratamen- to factível, segura e eficaz para pacientes de alto risco com estenose da valva aórtica grave sintomática. São necessários estudos adicionais, inclusive comparações diretas com a substituição cirúrgica da valva em diferentes populações de risco e avaliação da adequação desse dispositivo para pacientes com regurgitação aórtica predominante. No entanto, os progressos recentes já indicam que o implante percutâneo da válvula aórtica está evoluindo para um campo promissor e em rápida expansão da cardiologia intervencionista, e tem potencial para revolucionar os "padrões" atuais de tratamento da doença valvar aórtica.

\section{REFERÊNCIA BIBLIOGRÁFICA}

1. Sarmento-Leite R, Quadros AS, Prates PRL, Zanatta LG, Salgado Filho PA, Grando T, et al. Implante valvular aórtico percutâneo: experiência inicial do Sul do Brasil. Rev Bras Cardiol Invas. 2008;16(4):398-405. 